\title{
Discutindo a classificação periódica dos elementos e a elaboração de uma Tabela Periódica interativa
}

\section{RESUMO}

Olga Maria Schimidt Ritter olga.unioeste@gmail.com Universidade Estadual do Oeste do Paraná (Unioeste), Toledo, Paraná, Brasil

Marcia Borin da Cunha borin.unioeste@gmail.com Universidade Estadual do Oeste do Paraná (Unioeste), Toledo, Paraná, Brasil

Enio de Lorena Stanzani enio.stanzani@gmail.com Universidade Tecnológica Federal do Paraná (UTFPR), Apucarana, Paraná, Brasil

\begin{abstract}
A Tabela Periódica é uma ferramenta da ciência Química e seu conhecimento é parte importante para o ensino de Ciências, pois seu estudo e compreensão são considerados como fundamentais para entender vários conteúdos relacionados à Química. De modo geral, nas escolas, o conteúdo da Tabela Periódica é desenvolvido sem que haja uma reflexão maior sobre os fundamentos que a constituem, como a relação entre as propriedades dos elementos químicos e sua organização em forma de quadro. Neste artigo trazemos inicialmente, a confecção de uma Tabela Periódica com aproveitamento de material considerado descartável, e posteriormente, ser apresentada a análise de uma intervenção didática realizada com uma turma de ensino fundamental. A atividade aconteceu por meio de uma oficina do Projeto COMQUímICA das Crianças, a qual foi desenvolvida em dois momentos: inicialmente os estudantes procederam à organização de figuras geométricas, classificando-as de acordo com critérios escolhidos pelas crianças e, na sequência, trabalharam a organização da Tabela Periódica interativa, tendo em vista as propriedades dos elementos. Como resultado, pôde ser apontado que os estudantes, apesar de já terem estudado a Tabela Periódica, apresentaram visão ingênua sobre a organização e as propriedades dos elementos químicos e, nesse sentido, propostas como a aqui apresentada podem melhorar o ensino do conteúdo "Tabela Periódica", pois compreender critérios de classificação nos parece fundamental para entender os princípios que embasam a classificação periódica dos elementos.
\end{abstract}

PALAVRAS-CHAVE: Tabela Periódica. Ensino de Química. Atividade didática. 


\section{INTRODUÇÃO}

A chamada Tabela Periódica, em Química, é uma forma de organizar os elementos químicos até hoje conhecidos. Essa organização leva em conta as diversas características desses elementos, sendo uma ferramenta importante para a ciência Química e seu estudo. Na tabela estão sistematizadas informações sobre os elementos químicos. São informações que possibilitam prever o comportamento dos átomos como, por exemplo, a reatividade ou não de um determinado elemento químico.

Atualmente, a tabela está organizada a partir da estrutura atômica dos elementos químicos, mas ela foi originalmente desenvolvida por meio de observações experimentais das propriedades Químicas e físicas deles, observações essas realizadas especialmente nos séculos XVIII e XIX. Muitas tentativas de organização da Tabela Periódica foram propostas até chegarmos ao "modelo" utilizado atualmente. À medida que a ciência Química foi se desenvolvendo houve um aumento do número de novos elementos, bem como, novos materiais a disposição da população. Assim começou-se a pensar em um modo de organizar esses elementos e com isso foram delimitados alguns critérios para a sua organização.

Muitos cientistas das mais diferentes épocas e dos mais diversos países, tentaram estabelecer uma relação entre os elementos químicos que pudesse dar conta de uma organização que atendesse aos anseios da comunidade científica. Cada um desses cientistas tiveram uma importância, pois apesar do seu "modelo" de Tabela Periódica não ter sido aceito pela comunidade científica, todos eles contribuíram para que um dia Mendeleiev nos apresentasse aquele que perdurasse até os nossos dias.

A classificação mais detalhada dos elementos foi, pois, realizada pelo químico e físico russo - Dimitri Ivanovitch Mendeleiev - no ano de 1869, quando ele conseguiu ordenar os elementos químicos em ordem crescente de peso atômico (massa molar). Dessa organização resultaram as "famílias de elementos" e os "grupos". Na mesma época Meyer, na Alemanha, investigava as propriedades físicas dos elementos e constatou que valores semelhantes se repetiam periodicamente, quando a massa molar aumentava. Entretanto esta ideia foi revisada pelo cientista britânico Henry Moseley em 1913, que por meio de experiências com raios $X$ propôs a organização dos elementos por ordem de número atômico e não mais por massa atômica. Assim, a Tabela Periódica tem grande importância na ciência Química, já que nela temos a facilidade de acesso aos elementos químicos e suas propriedades de forma organizada.

No contexto escolar, podemos dizer que a importância da Tabela Periódica não se resume aos ensinos Fundamental e Médio, ou seja, para que os estudantes tenham uma noção básica dos elementos químicos, sua importância, constituição dos materiais etc., mas, sobretudo, para o conhecimento da Química enquanto ciência. Também para o Ensino Superior, especialmente nos cursos de Química e aqueles que têm essa ciência como base conceitual, o conhecimento sobre a Tabela Periódica, bem como do modo que o seu uso são importantes e essenciais, pois é a partir dela que os acadêmicos podem compreender os fenômenos químicos, bem como eles ocorrem. Além disso, é a partir das relações possíveis entre esses elementos que surgem diferentes reações e novas substâncias. 
Efetivamente, a disposição dos elementos, na forma de tabela, sintetiza informações e possibilita o acesso a essas informações, as quais podem ser utilizadas diariamente por um acadêmico, seja em atividades didáticas, seja em atividades de pesquisa.

Dentre os assuntos que têm relação direta com o estudo da Tabela Periódica podemos citar: ligações Químicas, propriedades físicas (solubilidade, ponto de fusão e ebulição), reatividade de compostos orgânicos (devido à eletronegatividade), conceitos de ácidos e bases etc. Neste sentido que pensamos ser importante que se conheça a Tabela Periódica e suas potencialidades, ou seja, que a conheçamos detalhadamente e que saibamos como tirar o maior número de informações disponíveis nesta tabela. Para que o estudante entenda como usar da melhor forma a Tabela Periódica acreditamos que esse conhecimento deve ser iniciado ainda no ensino fundamental, quando são apresentados aos estudantes os conhecimentos basilares da Química.

\section{A TABELA PERIÓDICA E AS ATIVIDADES DIDÁTICAS}

O estudo da Tabela Periódica faz parte dos programas de Ensino Fundamental, Médio e Superior, compondo parte dos livros didáticos de Ciências e de Química. $\mathrm{Na}$ maioria dos livros, o tratamento dado a esse conteúdo está centrado na distribuição eletrônica e na organização por famílias e grupos, deixando em segundo plano as propriedades e as características que servem para classificar os elementos químicos. É comum também, por parte de alguns professores, a utilização de esquemas com "regras de setas", o que não contribui para o entendimento das propriedades periódicas dos elementos. Além disso, pela forma como o conteúdo é apresentado, fica implícito que a tabela atual foi organizada apenas por Mendeleiev, desconsiderando todas as outras contribuições que resultaram nesta organização. É de se registrar, então, que a falta da compreensão histórica da constituição da Tabela Periódica e de outras propostas para a organização dos elementos químicos tem restringido a compreensão de uma ciência que se faz por meio de diversos atores e com peculiaridades de cada contexto social e cultural.

Uma breve observação nos livros didáticos já nos dá um panorama geral do que foi citado anteriormente. Na maioria dos livros não há uma discussão histórica do desenvolvimento da Tabela Periódica e, quando isso é feito, apenas é apresentada uma sequência linear dos acontecimentos, que passam a ideia de um conhecimento "pronto e acabado", feito por pessoas iluminadas ou por um acaso do destino, como a história que é contada aos estudantes sobre o "Sonho de Mendeleiev". Nos livros é apresentada uma elaboração da tabela como generalização indutiva de Mendeleiev, que carece de marco teórico por parte de quem a pensou. No caso dos livros didáticos que apresentam o marco histórico, da tabela, ainda temos um outro problema, como é o caso da não abordagem pelos professores da disciplina, ou seja, muitos se limitam a trabalhar em sala apenas a tabela de Mendeleiev.

Em pesquisa realizada por Mehlecke e colaboradores (2012), em livros didáticos de Química distribuídos no Programa Nacional do Livro Didático para o Ensino Médio, os pesquisadores verificaram que: 
[...] o conteúdo Tabela Periódica é parcialmente apresentado em uma perspectiva histórica. O contexto histórico aparece, geralmente, como recortes e figuras anexas. Ademais, há pouca relação entre esses anexos e os textos que explicam a própria Tabela Periódica. Dessa forma, não se apresenta de forma clara uma relação para os leitores e estudantes sobre como o conhecimento químico e físico sobre a Tabela Periódica evolui (MEHLECKE et al., 2012, p. 543).

A forma "mecânica e reprodutiva" das definições da Tabela Periódica geralmente tem um fim utilitário, ou seja, a resolução de exercícios. Sem uma compreensão adequada das propriedades periódicas e de suas variações, não há o entendimento da tabela e, consequentemente, não haverá a compreensão epistemológica das ciências. O estudo de regularidades e de semelhanças existentes entre os elementos químicos, bem como o entendimento dos critérios de classificação, é essencial para compreensão dos fundamentos da Tabela Periódica.

Nesse sentido, sendo o livro didático o principal recurso utilizado pelo professor para o ensino da Tabela Periódica, autores como Godoi e colaboradores (2010) e Franco-Mariscal e colaboradores (2009) apontam a relevância da utilização de métodos diversificados, como a Tabela Periódica interativa e jogos didáticos, buscando desconstruir a visão dos estudantes da necessidade de memorização das informações apresentadas, possibilitando, dessa forma, uma compreensão mais fundamentada e contextualizada do conteúdo em questão.

Diante desta perspectiva, Trassi e colaboradores (2001) afirmam que "[...] o estudo da Tabela Periódica, praticado em um grande número de escolas, [...] privilegia aspectos teóricos de forma tão complexa que se torna abstrato para o educando" (2001, p. 1335) e, nesse sentido, cabe ao professor proporcionar ao estudante uma abordagem que contemple conteúdos mais significativos, propriedades, aplicações e correlações entre esses assuntos, pois:

Ensinar corretamente ao aluno como a tabela foi construída significa ensinálo como o homem pensa em termos de ciência, para que, através das informações recebidas, o aluno possa chegar à compreensão unilateral da realidade e do papel da Química, não adquirindo tais informações passivamente (TRASSI et al., 2001, p. 1336).

Em artigo publicado na Revista Química Nova na Escola os autores César, Reis e Aliane (2015) apresentam uma Tabela Periódica interativa que foi construída no Centro de Ciências da Universidade Federal de Juiz de Fora. A referida tabela é constituída de:

[...] um móvel com o formato de uma Tabela Periódica, no qual amostras de 83 elementos químicos, em sua forma elementar, estão dispostas em caixas fechadas com vidros em que estão jateados símbolo, nome e número atômico dos elementos [...]. As caixas contêm também aplicações cotidianas dos elementos químicos (como remédios, cosméticos, peças eletrônicas etc.), bem como amostra de minerais dos quais se obtém cada elemento específico (CÉSAR; REIS; ALIANE, 2015, p. 182).

A proposta desses autores é relevante e demonstra uma preocupação em apresentar a Tabela Periódica aos visitantes do Centro de Ciências da UFJF, de forma que estes possam observar elementos e propriedades desses elementos, de forma interativa. Assim, este tipo de material pode promover uma melhor 
aprendizagem sobre o conteúdo da Tabela Periódica. Entretanto, o acesso a este local é restrito à região de Juiz de Fora, Minas Gerais, Brasil, o que implica em uma proposta que atinge um número limitado de pessoas e estudantes. Por outro lado, a apresentação da Tabela Periódica nas escolas ainda carece de propostas e de atividades motivadoras e que não necessitem que os estudantes precisem visitar centros de pesquisa e museus de ciências, pois que como sabemos, esses espaços ainda são poucos e localizados quase que somente em capitais e em grandes centros urbanos.

Com a intenção de propor metodologias e recursos didáticos que facilitem o aprendizado dos estudantes com relação à Tabela Periódica é que têm surgido muitos jogos como por exemplo no artigo de Godoi, Oliveira e Godognoto (2010), no qual os autores relataram a adaptação feita no jogo "Super Trunfo" (vendido comercialmente) para trabalhar as propriedades da Tabela Periódica e a distribuição eletrônica.

Tendo em vista os pontos até aqui apresentados, nosso trabalho traz a proposta de construção de uma Tabela Periódica interativa com material reutilizável, o que pode ser facilmente obtido e confeccionado em qualquer escola.

Assim, apresentamos inicialmente a construção da Tabela Periódica e só, posteriormente elaboramos uma análise de uma intervenção didática com esse material, intervenção essa que foi desenvolvida com estudantes do 9o ano do Ensino Fundamental. As atividades desenvolvidas tiveram como propósito a apresentação dos elementos químicos, por meio da compreensão dos critérios de classificação desses elementos e a organização dos mesmos, de acordo com as suas semelhanças e relações.

\section{METODOLOGIA}

\section{ETAPAS DE ELABORAÇÃO DOS MATERIAIS}

A seguir, serão apresentados os materiais e os procedimentos para a elaboração dos recursos que serão utilizados nas propostas didáticas aqui relatadas.

a) Kit de figuras geométricas: critérios de organização

Para a realização da atividade é necessário preparar os "kits" que são distribuídos aos grupos de estudantes. Cada kit contém 97 peças, sendo composto por diferentes formas geométricas recortadas em papel tipo EVA, em cinco cores diferentes (vermelho, verde, amarelo, branco e laranja). O Quadro 1 traz a relação das figuras geométricas que constituem o kit e, na Figura 1, as formas confeccionadas. 
Quadro 1 - Relação das figuras geométricas que constituem o kit

\begin{tabular}{c|c|c|c}
\hline Figura Geométrica & $\begin{array}{c}\text { Quantidade de } \\
\text { Cores }\end{array}$ & $\begin{array}{c}\text { Quantidade de } \\
\text { tamanhos }\end{array}$ & Total \\
\hline Quadrado & 04 & 03 & 12 \\
\hline Retângulo & 04 & 03 & 12 \\
\hline Triângulo equilátero & 04 & 03 & 12 \\
\hline Triângulo retângulo & 04 & 03 & 12 \\
\hline Losango & 04 & 03 & 12 \\
\hline Trapézio & 04 & 03 & 12 \\
\hline Círculo & 04 & 03 & 12 \\
\hline Circunferência & 04 & 03 & 12 \\
\hline Hexagrama (Estrela) & 01 & 01 & 01 \\
\hline \multicolumn{2}{c}{ Total de figuras }
\end{tabular}

Fonte: Autoria própria (2017).

A montagem dos kits caracteriza-se apenas como sugestão, podendo ser utilizado outro tipo de material, como por exemplo: botões de roupa de diferentes cores, tamanhos e formas ou mesmo macarrão em diferentes formatos e cores.

Figura 1 - Figuras geométrica com tamanhos e formas diferentes

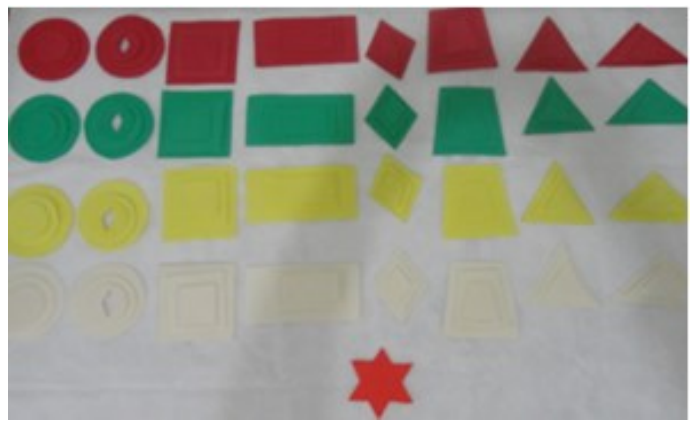

Fonte: Arquivo próprio (2017).

b) Construção da Tabela Periódica Interativa

Na sequência, apresentamos os passos para a construção de uma Tabela Periódica interativa confeccionada com material reutilizável. Os materiais necessários encontram-se listados no Quadro 2.

Quadro 2 - Materiais utilizados na confecção da tabela

\begin{tabular}{c|c}
\hline Quantidade & Material \\
\hline 118 & ${\text { Embalagens de leite/suco (Tetra Pak }{ }^{\circledR} \text { ) quadradas vazias }}^{\text {Tesoura }}$ \\
\hline-- & Papel sulfite \\
\hline-- & Papel contact \\
\hline-- & Fonte: Autoria própria (2017)
\end{tabular}

Os elementos são organizados em forma de cubos, confeccionados com embalagens de leite longa vida, que são descartadas como lixo doméstico.

Para a construção dos cubos são necessárias algumas etapas, as quais serão 
1. Lave as embalagens vazias e corte-as, produzindo um cubo (todos os lados com $7,0 \mathrm{~cm})$, conforme a Figura 2:

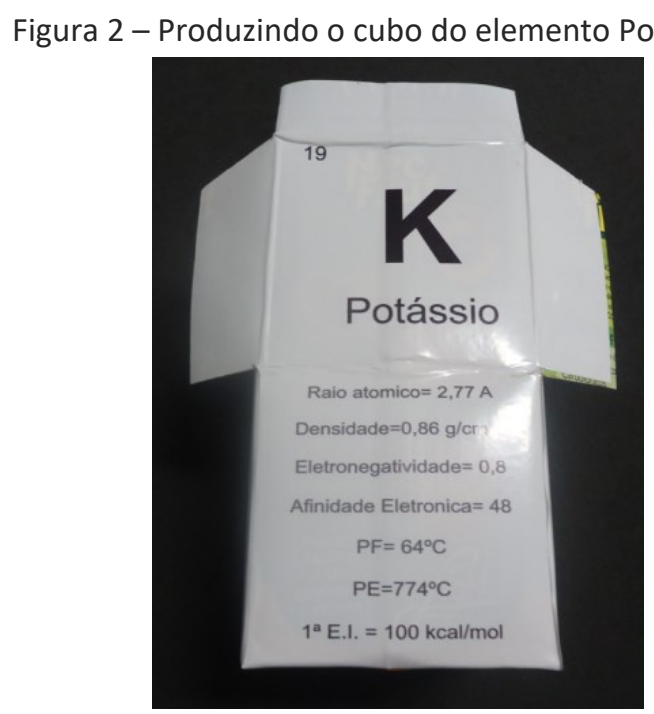

Fonte: Autoria própria (2017).

Em cada uma das seis faces do cubo devem ser adicionadas algumas informações sobre o elemento químico. Em nossa organização optamos por:

Face 1: símbolo, nome do elemento e número atômico;

Face 2: propriedades periódicas;

Face 3: ocorrência do elemento;

Face 4: estado físico e radiatividade;

Face 5: classificação periódica (metal, não metal, gases nobres, alcalinos, alcalinos terrosos, calcogênios ou halogênios);

Face 6: símbolo, nome do elemento em latim e massa atômica.

As faces podem ser elaboradas em papel sulfite e fixadas ao cubo com auxílio do papel contact, resultando em cubos como os da Figura 3.

Figura 3 - Cubos dos elementos confeccionados a partir de embalagens de leite/suco

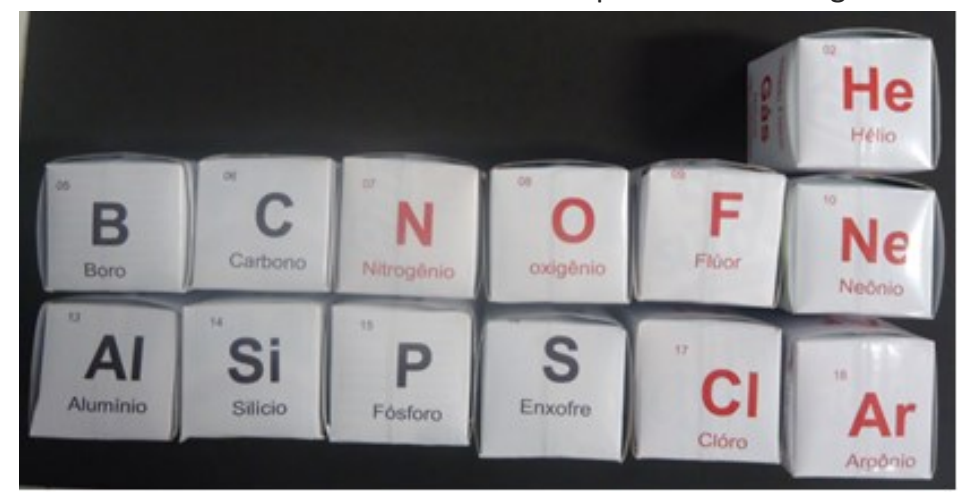

Fonte: Autoria própria (2017). 
Para a disposição dos cubos e sua organização dos mesmos foi confeccionado um painel em madeira com encaixe para cada um dos elementos. $O$ painel foi confeccionado por um marceneiro e pode ser visualizado nas Figuras 4 e 5 .

Figuras 4 e 5: Faces "Símbolo do elemento e número atômico" e "Ocorrência"

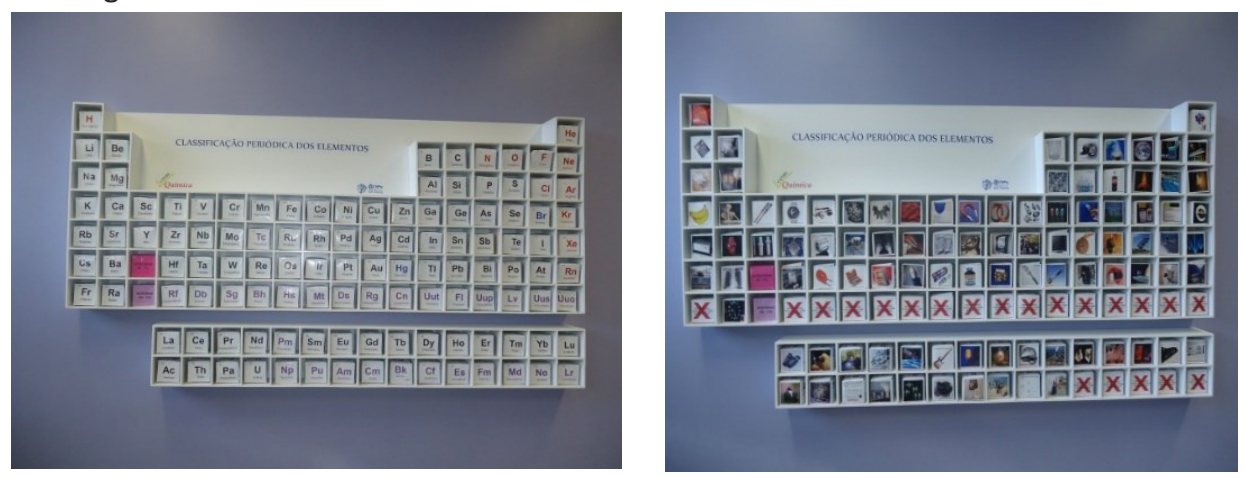

Fonte: Autoria própria (2017).

c) Atividade com a Tabela Periódica

Como proposta de atividade de apresentação e discussão da Tabela Periódica, organizamos duas etapas para o seu desenvolvimento.

A primeira etapa constitui-se da utilização do kit com figuras geométricas, com as quais os estudantes deveriam interagir diretamente com o material, discutindo e elaborando critérios para a classificação das figuras a eles disponibilizadas. A ideia aqui é que os estudantes reflitam sobre formas possíveis de organização de um material qualquer, pois isso implica em transpor essa ideia para a organização dos elementos da Tabela Periódica. A definição de critérios é algo a ser desenvolvido junto aos estudantes, pois os cientistas utilizam critérios a condução de atividades científicas. Para conduzir essa primeira etapa, apresentamos a seguinte questão problema: Quais são os critérios possíveis para a classificação do material disponível?

Na segunda etapa, o trabalho foi a manipulação direta com a tabela interativa, que se encontrava no laboratório COMQUíMICA das crianças (Núcleo de Ensino de Ciências de Toledo, NECTO, Unioeste). Cada elemento (caixinha) foi retirado do quadro, no qual estava alocado, e de modo aleatório distribuímos os elementos químicos aos grupos de estudantes. Estes estudantes deveriam propor uma organização dos elementos em torno de critérios que eles considerassem pertinentes. Nesse sentido, apresentamos a seguinte questão: Como vocês organizariam esses elementos, vislumbrando critérios de organização?

Nessa segunda etapa os estudantes deveriam discutir em grupo as possibilidades de organização do material e compartilhar suas ideias com toda a turma. Para conduzir a discussão na turma apresentamos as questões: Que critérios vocês podem utilizar para organizar os elementos? Como será que os cientistas chegaram até a organização atual da Tabela Periódica dos elementos químicos?

Essa condução didática tem como fundamento a discussão das possibilidades de organização dos elementos, levando os estudantes a refletirem sobre a organização da tabela atual. 


\section{RESULTADOS E DISCUSSÃO}

\section{INTERVENÇÃO DIDÁTICA COM A TABELA PERIÓDICA INTERATIVA}

Neste tópico descrevemos e analisamos duas atividades relacionadas à Tabela Periódica, uma trabalhando os critérios de organização, para isso utilizando os kits de figuras geométricas feitas em EVA e uma segunda que busca articular com a primeira atividade (critérios de organização) a organização dos elementos na Tabela Periódica, de acordo com as propriedades e as informações presentes em cada cubo.

A atividade foi desenvolvida com 45 estudantes do 9 o ano do ensino fundamental, de uma escola particular, da cidade de Toledo, Paraná. Esta foi realizada no Laboratório COMQUÍMICA da Universidade Estadual do Oeste do Paraná (Unioeste), quando os estudantes participavam de oficinas oferecidas no projeto de extensão COMQUímICA das crianças. Esse projeto foi planejado com o objetivo de inserir as crianças no "mundo" da ciência, trazendo a elas um pouco do conhecimento químico, pois a escola, no nível fundamental de ensino, normalmente trabalha com assuntos voltados aos conhecimentos biológicos, deixando os conhecimentos da Química e da física em último plano ou totalmente esquecidos. Temos como pressuposto do projeto que o espaço da universidade pode ser um local para o desenvolvimento de atividades com crianças e que essa pode ser uma forma de contribuir para a formação de atitudes científicas desde muito cedo na vida das crianças. Assim, conteúdos de Ciências/Química são discutidos por meio de oficinas, cuja metodologia segue aspectos do Ensino por investigação. Docentes e acadêmicos pertencentes ao Curso de Química da Unioeste, e que desenvolvem atividades no Núcleo de Ensino de Ciências de Toledo-NECTO, elaboram as oficinas, que são previamente testadas. As oficinas são oferecidas às escolas da cidade de Toledo e da região, que entram em contato para agendar a visita das crianças na sala do NECTO (laboratório COMQUÍMICA).

A metodologia das oficinas segue uma abordagem investigativa. Essa abordagem possibilita trabalhar a autonomia e a capacidade dos estudantes para tomarem decisões, por meio da reflexão, da avaliação, da resolução de problemas e do uso de conceitos e de teorias das ciências. $O$ ensino por investigação é uma metodologia que busca respostas às situações problemas, as quais podem ser propostas por meio de questões problematizadoras. Estas questões orientam a condução da atividade e promovem espaços de discussão e de interação entre estudantes e entre estudante e professor.

O papel do professor no ensino por investigação é de guia e condutor das atividades. É ele quem propõe e discute questões, orienta a proposição de hipóteses e de questões teóricas, induz conceitos, auxilia na argumentação dos estudantes e promove a sistematização do conhecimento.

Em uma destas oficinas apresentamos e discutimos com estudantes do 9o ano do Ensino Fundamental alguns aspectos referentes à constituição da Tabela Periódica.

Destacamos que o conteúdo de Tabela Periódica já havia sido trabalhado pela professora em sala de aula. Dessa forma, a princípio, os estudantes deveriam ter conhecimento do que íamos discutir, fato este que se mostrou inusitado em 
muitos momentos. Com o desenvolvimento da atividade percebemos que os estudantes apresentavam ideias equivocadas, com pouca compreensão dos fundamentos da organização dos elementos e com relação ao contexto histórico observamos que os mesmos não apresentavam nenhum conhecimento.

A atividade de intervenção didática foi realizada com a distribuição da turma em grupos. Nesses grupos, os estudantes interagiam entre si e, posteriormente, traziam para o grupo maior as considerações e os acordos estabelecidos nos grupos. Assim tivemos a constituição de nove grupos, com cinco estudantes em cada grupo.

O registro da atividade foi feito por meio de diário, no qual os pesquisadores discutiram em grupo e descreveram a atividade em momento posterior à oficina.

A fim de organizar o processo de análise e de discussão, os resultados de cada uma das atividades vão apresentados separadamente.

\section{a) Atividade 1: critérios de organização}

Inicialmente, a seguinte questão foi colocada aos participantes: Quais são os critérios possíveis para separação do material disponível?

Para iniciar esta atividade foram distribuídos os kits aos estudantes (reunidos em grupos) contendo figuras de diferentes formas geométricas, de diferentes tamanhos e cores. Cada um dos grupos estabeleceu critérios para organizar as figuras em categorias que, posteriormente, foram discutidos com o grande grupo.

Os estudantes podiam estabelecer diferentes critérios para a organização, como: cor, forma geométrica, tamanho, número de lados da figura, dentre outros. A ideia é que os estudantes visualizassem as diferentes possibilidades de separação e organização das figuras, assim como fizeram os cientistas, que, por meio de suas pesquisas, chegaram à organização da Tabela Periódica.

Na Figura a seguir 6 trazemos a imagem dos estudantes, quando eles estavam elaborando a classificação das figuras disponíveis.

Figura 6 - Organização por cores, formas e tamanhos

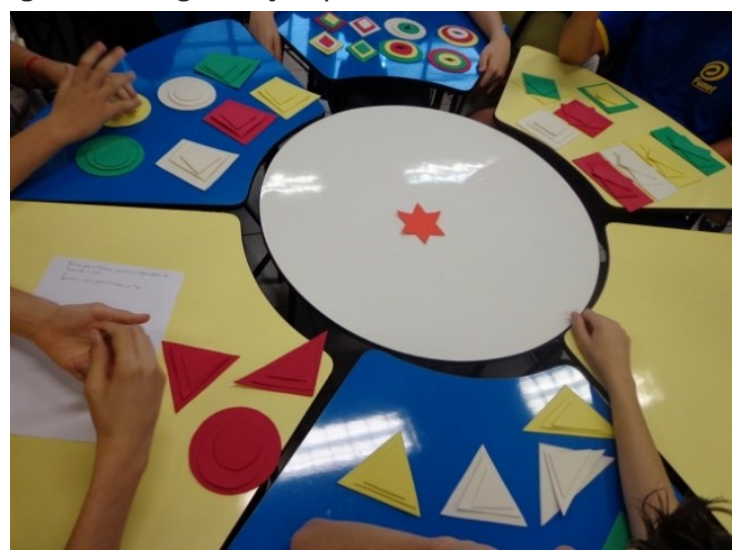

Fonte: Arquivo próprio (2017).

Durante a atividade, os estudantes realizaram a distribuição das figuras geométricas definindo um critério geral e critérios secundários. O critério geral 
predominante definido pelos estudantes foi "cor", escolhido por sete (7) grupos, seguido por critérios secundários como: formas geométricas e tamanho (do menor para o maior).

Dois (2) grupos escolheram como critério geral o número de lados das figuras geométricas, por exemplo, 4 lados (quadrado, retângulo e losango), 3 lados (triângulos) e sem lados, separando assim as figuras em 3 grupos. Nesses dois grupos, os estudantes ainda separaram por cor e tamanho (critérios secundários).

Um (1) grupo classificou as figuras em apenas dois (2) grandes grupos: grupo 1: com pontas (quadrados, retângulos, losango e estrela); grupo 2: sem pontas (círculos).

$\mathrm{Na}$ atividade de classificação das figuras pudemos perceber que o número de possibilidades de organização propostas variou de um grupo para o outro e que esta variação está diretamente ligada ao interesse e à participação do grupo, sendo que a discussão no grupo fez com que os estudantes pensassem sobre a definição de critérios que poderiam abranger um maior número de componentes.

Os estudantes, de modo geral, inicialmente, sentiram um pouco de dificuldade em estabelecer os critérios, pois o número de formas e cores no kit é bem amplo. Entretanto, após o manuseio e a discussão com os colegas, eles começaramm a compreender a dinâmica da atividade e conseguiram estabelecer conexões e relações, organizando-as.

Para registro da atividade solicitamos que cada grupo fizesse uma anotação por escrito, na qual deveriam fazer constar todos os critérios estabelecidos pelo grupo para organizar as figuras.

Para sistematizar o conhecimento e conduzir a discussão com os estudantes (grande grupo) solicitamos que eles, apresentassem os critérios estabelecidos e os motivos que os levaram a essas escolhas. Cada grupo apresentou sua classificação e, após, buscamos questioná-los sobre o que "faz" com que as escolhas sejam diferentes e o que significa o estabelecimento de um critério na ciência. Nossa intenção foi trazer aos estudantes não apenas a ideia de organização por meio de critérios, mas também deixar claro que o critério é provisório e que a ciência assim também é.

Considerando a escolha de critérios e a provisoriedade, conduzimos a discussão para a questão dos elementos químicos e sua organização, e o fizemos a partir dos seguintes questionamentos: Por que existe a Tabela Periódica? Como os elementos foram organizados na Tabela Periódica? Há algum(ns) critério(s) para essa organização? Essa organização pode ser alterada?

Nessa discussão, os estudantes apontaram que a Tabela Periódica foi elaborada para se ter uma organização dos elementos e que esses elementos estão organizados em grupos e em períodos. Não souberam falar sobre as propriedades dos elementos, nem sobre os critérios de organização da Tabela Periódica atual. Também relataram que a tabela foi elaborada por um "cara" que sonhou com os elementos e depois os colocou em ordem. Não conheciam outras formas de organização da Tabela Periódica (não conheciam a história mais ampla do assunto) e, assim, não imaginavam que poderiam existir outras formas a não ser a proposta por Mendeleiev. 
Os estudantes citaram que, durante a aula de Química na escola, eles haviam assistido a um vídeo, no qual um cientista sonhou com a organização dos elementos e que desse sonho surgiu a Tabela Periódica.

Tendo em vista algumas ideias equivocadas dos estudantes, discutimos com eles que o "sonho de Mendeleiev" é apenas uma história que se conta e que não sabemos o quanto ela é verídica. Mendeleiev estava refletindo sobre possibilidades de organização da tabela (assim como outros cientistas da mesma época) e talvez tenha sonhado com algum tipo de organização para os elementos, pois uma mente cansada e preocupada com um problema acaba por revelar-se em sonhos, mas que a ciência não opera com sonhos.

\section{b) Atividade 2: Trabalhando com a Tabela Periódica}

Novamente uma questão inicial foi proposta aos alunos: Como será que os cientistas chegaram até a organização atual da Tabela Periódica dos elementos químicos? Que critérios os cientistas usaram para organizar os elementos?

Depois da separação das figuras geométricas cada grupo recebeu um número de cubos que representavam os elementos químicos. O número de cubos que cada grupo recebeu dependia do número de estudantes que participaram da atividade. Os estudantes discutiram as possibilidades de agrupamento dos cubos, baseados nas informações contidas em cada face de cada cubo.

Para possibilitar uma melhor organização, tendo como base as semelhanças entre as propriedades, distribuímos aos grupos elementos químicos que apresentavam relação entre suas propriedades.

Durante a organização acompanhamos as discussões nos grupos, buscando relacionar a organização da Tabela Periódica com a primeira atividade (distribuição das figuras geométricas). Os estudantes discutiram a organização dos elementos, procurando nos cubos as propriedades dos elementos que apresentavam semelhanças, conforme pode se verificar na Figura 7.

Figura 7 - Estudantes analisando as semelhanças entre as propriedades dos elementos

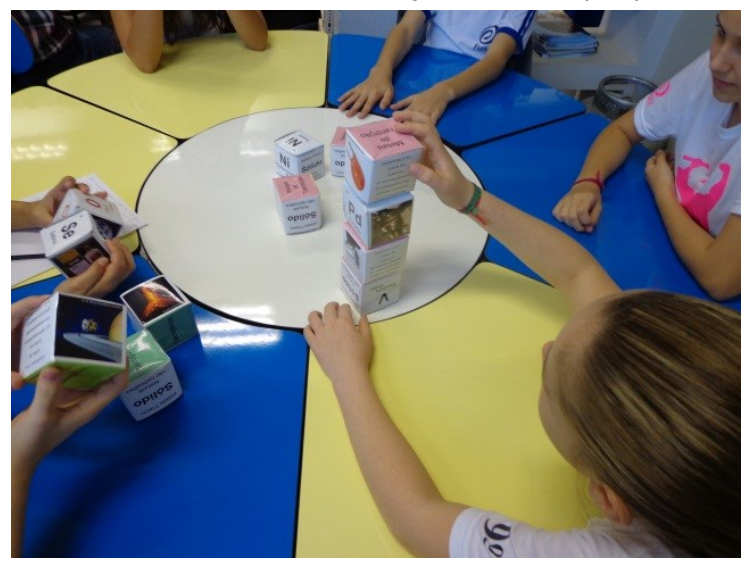

Fonte: Arquivo próprio (2017).

A lista de critérios elencados pelos estudantes encontra-se no Quadro 3, conjuntamente com os critérios utilizados por cada um dos grupos para a classificação dos elementos químicos. 
Nesse quadro é possível perceber que forma vários critérios foram elencados pelos estudantes, demostrando um conhecimento sobre a tabela e os elementos químicos que a fazem parte da mesma. Podemos perceber que alguns dos critérios se repetiram, porém tivemos um diversificado número de critérios estabelecido pelo grupo de estudantes.

Quadro 3-Critérios elencados pelos estudantes

\begin{tabular}{c|c|c|c}
\hline Código & Critérios & Código & Critérios \\
\hline C01 & $\begin{array}{c}\text { Estado físico (sólido, gases e } \\
\text { líquidos }\end{array}$ & C10 & Sólido radioativo ou não \\
\hline C02 & Afinidade eletrônica & C11 & $\begin{array}{c}\text { Grupo que brilha e que não } \\
\text { brilha }\end{array}$ \\
\hline C03 & $\begin{array}{c}\text { Ponto de fusão negativo e } \\
\text { positivo }\end{array}$ & C12 & Aplicação \\
\hline C04 & Densidade & C13 & Raio atômico \\
\hline C05 & Número atômico & C14 & Ponto de ebulição \\
\hline C06 & Famílias & C15 & Condutividade \\
\hline C07 & Eletronegatividade & C16 & Massa \\
\hline C08 & Radioativo ou não & C17 & Ordem alfabética \\
\hline C09 & Artificial radioativo ou não & C18 & Camada de valência \\
\hline
\end{tabular}

Fonte: Autoria própria (2017).

No Quadro 4 apresentamos o código dos critérios (apresentados no Quadro 3 ) e as opções de escolha de cada grupo, pois os grupos tentaram organizar os elementos relacionando com mais de um critério, conforme apresentado no quadro anterior. Assinalamos com " $X$ " os critérios considerados por cada grupo de estudantes.

Quadro 4-Critérios utilizados pelos grupos (G) para organização das caixas

\begin{tabular}{c|c|c|c|c|c|c|c|c|c|c}
\hline Critério & $\mathrm{G} 1$ & $\mathrm{G} 2$ & $\mathrm{G} 3$ & $\mathrm{G} 4$ & $\mathrm{G} 5$ & $\mathrm{G} 6$ & $\mathrm{G} 7$ & $\mathrm{G} 8$ & $\mathrm{G9}$ & $\mathrm{G} 10$ \\
\hline $\mathrm{C} 01$ & $\mathrm{X}$ & & & $\mathrm{X}$ & $\mathrm{X}$ & $\mathrm{X}$ & $\mathrm{X}$ & $\mathrm{X}$ & $\mathrm{X}$ & $\mathrm{X}$ \\
\hline $\mathrm{C} 02$ & $\mathrm{X}$ & $\mathrm{X}$ & $\mathrm{X}$ & & & & & $\mathrm{X}$ & & $\mathrm{X}$ \\
\hline $\mathrm{C} 03$ & & & & $\mathrm{X}$ & & & $\mathrm{X}$ & $\mathrm{X}$ & & \\
\hline $\mathrm{C} 04$ & $\mathrm{X}$ & & & $\mathrm{X}$ & & $\mathrm{X}$ & $\mathrm{X}$ & $\mathrm{X}$ & $\mathrm{X}$ & \\
\hline $\mathrm{C} 05$ & $\mathrm{X}$ & & & & & $\mathrm{X}$ & $\mathrm{X}$ & $\mathrm{X}$ & $\mathrm{X}$ & $\mathrm{X}$ \\
\hline $\mathrm{C} 06$ & $\mathrm{X}$ & & $\mathrm{X}$ & $\mathrm{X}$ & $\mathrm{X}$ & & $\mathrm{X}$ & $\mathrm{X}$ & $\mathrm{X}$ & $\mathrm{X}$ \\
\hline $\mathrm{C} 07$ & & $\mathrm{X}$ & & $\mathrm{X}$ & & & & $\mathrm{X}$ & $\mathrm{X}$ & \\
\hline $\mathrm{C} 08$ & & $\mathrm{X}$ & & & $\mathrm{X}$ & & $\mathrm{X}$ & $\mathrm{X}$ & $\mathrm{X}$ & \\
\hline $\mathrm{C} 09$ & & $\mathrm{X}$ & & & & & & & & $\mathrm{X}$ \\
\hline $\mathrm{C} 10$ & & $\mathrm{X}$ & & & & & & & & \\
\hline $\mathrm{C} 11$ & & & & & $\mathrm{X}$ & & & & & \\
\hline $\mathrm{C} 12$ & & & & & & $\mathrm{X}$ & & & & \\
\hline $\mathrm{C} 13$ & & & & & & $\mathrm{X}$ & & & & \\
\hline $\mathrm{C} 14$ & & & & & & & $\mathrm{X}$ & $\mathrm{X}$ & & \\
\hline $\mathrm{C} 15$ & & & & & & & $\mathrm{X}$ & & & \\
\hline $\mathrm{C} 16$ & & & & & & & & $\mathrm{X}$ & & \\
\hline $\mathrm{C} 17$ & & & & & & & & $\mathrm{X}$ & & \\
\hline $\mathrm{C} 18$ & & & & & & & & $\mathrm{X}$ & $\mathrm{X}$ & \\
\hline
\end{tabular}

Fonte: Autoria própria (2017).

Os estudantes consideraram 18 critérios para pensar em uma organização por semelhança entre as propriedades, sendo o critério predominante foi o estado 
físico dos elementos e famílias. Essa escolha pode estar relacionada ao nível de ensino em que esses estudantes se encontram (ensino fundamental) e, no qual, o estudo do estado físico é um aspecto mais concreto e presente nos conteúdos escolares. Quanto à escolha das famílias dos elementos foi possível perceber que esta classificação havia sido apresentada pela professora da classe e, portanto, já fazia parte de um "conhecimento" que estes estudantes trouxeram para oficina. Isso também apareceu na fala dos estudantes quanto à organização da Tabela Periódica por número atômico e que se encontra com frequência no quadro acima. Por outro lado, propriedades como eletronegatividade, camada de valência, raio atômico, ponto de ebulição e outros são pouco considerados pelos estudantes.

A partir das discussões a respeito das possibilidades de organização dos elementos por meio de suas propriedades, os estudantes deveriam reunir todos os elementos, propondo uma organização geral da Tabela Periódica, colocando os cubos no painel. Cada grupo foi até o painel e colocou os elementos que estavam com o grupo, de modo a constituir para eles uma organização para os mesmos (Figura 8). Caso o(s) estudante(s) não concordasse(m) com a posição dos elementos colocada pelo grupo anterior, estes poderiam mudar a posição do cubo poderia ser mudada e com isso fazer uma nova distribuição até que se chegasse a um consenso geral da turma.

Figura 8 - Estudantes interagindo com a Tabela Periódica e propondo uma organização

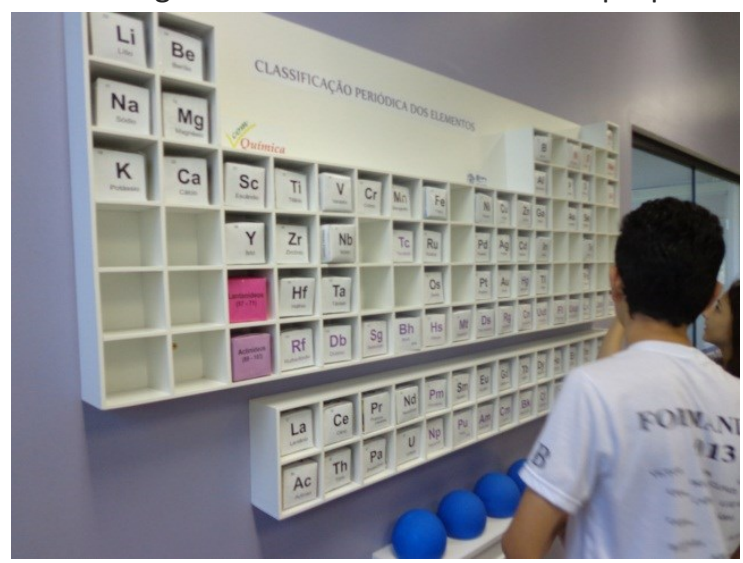

Fonte: Arquivo próprio (2017).

Ao final da atividade questionamos os estudantes sobre o nome "Tabela Periódica dos elementos químicos".

Como esses estudantes já haviam estudado esse conteúdo na escola, julgamos que seria uma pergunta tranquila para eles responderem. Entretanto, observamos que haviam ideias equivocadas referentes ao fato da tabela ser chamada de "periódica".

Os estudantes afirmaram que esse nome faz referência aos períodos da tabela. Em vista disso perguntamos se a organização que eles fizeram na atividade havia levado em conta as propriedades dos elementos. A resposta foi afirmativa. Então, perguntamos: Qual é a relação das propriedades com os períodos? Os estudantes não conseguiram responder. Insistimos na questão e um deles nos respondeu que não havia relação com os períodos, mas com os grupos, pois foi por meio de um grupo que se pôde organizar os elementos e reuni-los em propriedades semelhantes. Então perguntamos a eles o que poderia significar o 
nome "periódico", se não havia relação direta das com os períodos. Não obtivemos resposta.

A fim de buscar uma compreensão, utilizamos uma analogia mediante uma pergunta: O que é ir ao dentista periodicamente? E a resposta foi: "ir de tempos em tempos", "ir em um determinado período". A partir dessas respostas voltamos à questão de a tabela ser chamada de "periódica", ou seja, destacando que as propriedades se repetem com certa periodicidade.

Com esse tipo de atividade problematizadora e fundamentada em um processo investigativo, podemos perceber que para um conteúdo como "Tabela Periódica", é preciso que apresentemos aos estudantes os fundamentos que constituem a organização dos elementos em forma de tabela, pois sem estes é muito difícil que um aluno venha a compreender o real significado da organização dos elementos, bem como a sua correta utilização. Além disso, o contexto histórico é necessário e pertinente quando se pretende apresentar a Química como um processo de construção de conhecimento e não como produto de "iluminados". Nesse sentido, fica claro que são necessárias abordagens para Tabela Periódica mais dinâmicas e interativas, abordagens que problematizem o conhecimento e sua construção histórica. Aos estudantes é essencial que estes não "decorem" (não memorizem) a posição dos elementos e suas propriedades periódicas e aperiódicas, mas que entendam o porquê da tabela e tudo o que envolvem a sua organização. $O$ conteúdo Tabela Periódica vai muito além de saber sua função, pois nela estão implicados o papel do cientista e o das pesquisas e as relações entre critérios estabelecidos por essas pesquisas.

\section{CONSIDERAÇÕES FINAIS}

A Tabela Periódica interativa constitui-se como um elemento importante para a apresentação desse conteúdo aos estudantes, tendo em vista que a abordagem desenvolvida prioriza a identificação de critérios e de semelhanças entre as propriedades dos elementos químicos, o que é um assunto de extrema importância para o entendimento da organização da Tabela Periódica.

A atividade realizada com jovens do 9 ㅇ ano do ensino fundamental possibilitou a abertura de discussões entre os estudantes e a compreensão da Tabela Periódica como uma das formas de organização e não a única possibilidade (que era a ideia geral dos estudantes ao chegar no laboratório COMQUÍMICA).

Nesse sentido, é importante destacar que atividades como esta serão tão mais eficientes quanto maior for o comprometimento do professor e o dos estudantes na organização do material e na realização consciente e refletida sobre a atividade. Sugerimos que este tipo de atividade seja para a introdução do conteúdo da Tabela Periódica, pois compreender critérios de classificação dos elementos nos parece fundamental para entender os princípios que embasam a classificação periódica dos elementos. 


\title{
Discussing the periodic classification of the elements and the elaboration of an interactive periodic table
}

\begin{abstract}
The periodic table is a tool of chemical science and its knowledge is part of activities developed at school, since its study and understanding area considered as fundamental to understand chemistry. In general, in the schools, the content of the Periodic Table its developed without major reflections about the foundations that constitute it, such as the relation between the properties of the chemical elements and their organization in the form of a frame. In this article, we first present the construction of a Periodic Table using material considered junk and then we present the analysis of a didactic intervention, accomplished with a class of Elementary School. The activity was propose in a workshop of the COMQUIMICA Project and developed in two stages: first, the students made the organization of geometric figures classifying them according to chosen by them. Further, the organization worked the interactive periodic table, given the properties of the elements contained in the cubes. As result, we point the vision of students to exteriorize the initial ideas about the organization and properties of chemical elements in the periodic table and, accordingly, proposals like this are effective for teaching knowledge about the periodic table, once the understanding classification criteria seems to us fundamental to understand the principles that base the periodic classification of the elements.
\end{abstract}

KEYWORDS: COMQUÍMICA Project. Periodic table. Chemistry teaching. 


\section{REFERÊNCIAS}

CÉSAR, E. T.; REIS, R. de C.; ALIANE, C. S. de M. Tabela Periódica interativa. Revista Química Nova na Escola, v. 37, n. 3, p. 180-186, 2015.

FRANCO-MARISCAL, A. J.; CANO-IGLESIAS, M. J. Soletrando Br-As-I-L com símbolos químicos. Revista Química Nova na Escola, v. 31, n. 1, p. 31-33, 2009.

GODOI, T. A. F.; OLIVEIRA, H. P. M.; CODOGNOTO, L. Tabela Periódica - um super trunfo para alunos do ensino fundamental e médio. Revista Química Nova na Escola, v. 32, n. 1, p. 22-25, 2010.

MEHLECKE, C. M.; EICHLER, M. L.; SALGADO, T. D. M.; DEL PINO, J. C. A. abordagem histórica acerca da produção e da recepção da Tabela Periódica em livros didáticos brasileiros para o ensino médio. Revista Electrónica de Enseñanza de las Ciencias, v. 11, n. 3, p. 521-545, 2012.

TRASSI, R. C. M.; CASTELLANI, A. M.; GONÇALVES, J. E.; TOLEDO, E. A. Tabela Periódica interativa: um estímulo à compreensão. Acta Scientiarum, v. 23, n. 6, p. 1335-1339, 2001. Disponível em: http://periodicos.uem.br/ojs/index.php/ ActaSciTecnol/article/view/2757. Acesso: 20 de setembro de 2017.

Recebido: 29 mai. 2017

Aprovado: 21 ago. 2017

DOI: $10.3895 /$ actio.v2n1.6782

Como citar:

RITTER, O. M. S.; CUNHA, M. B. da; STANZANI, E. de. L. Discutindo a classificação periódica dos elementos e a elaboração de uma Tabela Periódica interativa. ACTIO, Curitiba, v. 2, n. 1, p. 359-375, jan./jul. 2017. Disponível em: <https://periodicos.utfpr.edu.br/actio>. Acesso em: XXX.

Correspondência:

Olga Maria Schimidt Ritter

Rua da Faculdade, 645, Bairro Jardim Santa Maria, Cep 85903 000, Toledo-PR, Brasil.

Direito autoral: Este artigo está licenciado sob os termos da Licença CreativeCommons-Atribuição 4.0

Internacional.

(c) (i) 